\title{
Spacecraft Pitch PID Controller Tunning using Ziegler Nichols Method
}

\author{
Lama Mohammed ${ }^{1}$, Muawia Mohamed Ahmed ${ }^{2}$ \\ P.G. Student, Department of Control Engineering, Faculty of Engineering, El.Neelain University, Khartoum, \\ Sudan, \\ Associate Professor, Department of control Engineering, Faculty of Engineering, El.Neelain University, \\ Khartoum, Sudan,
}

Abstract: The issue of finding the optimal parameters of the PID controller for any system to optimize the system behaviour is almost difficult and takes more time. In control field there are many techniques used for this purpose. This paper discusses Ziegler Nicholas method techniques to obtain the specific range of the optimal parameters for the space craft pitch altitude.

Keywords: space craft, pitch, TF, PID, Ziegler Nichols.

\section{Introduction}

The process of selecting the controller parameters to meet a given performance specifications is known as controller tuning, and PID controller is one of that Controller Tunning.

There are two main techniques to design and set the gain or parameters in PID controller, the first and simplest one is the manual tuning technique; and the second one is the Ziegler-Nichols tuning method.

Manual tuning can be very effective but requires some amount of experience and understanding of PID circuits and responses. Ziegler-Nichols method tuning offers a bit more structured guide to setting PID parameters values.

Ziegler and Nichols suggested rules for tuning PID controllers (meaning to set values $\mathrm{Kp}, \mathrm{Ti}$, and $\mathrm{Td}$,) based on experimental step responses or based on the value of $\mathrm{Kp}$, that results in marginal stability when only proportional control action is used.

\section{Background Theory}

To apply any control tunning technique to control the rotation of the pitch aircraft controller must obtain the mathematical model for pitch aircraft system after that can get the pitch transfer function to represent the pitch aircraft system.

The pitch transfer function for high altitude is [1]:

$\mathrm{Gp}=$ 3.6

$$
(\mathrm{s} 4+3.36 \mathrm{~s} 3+4.08 \mathrm{~s} 2+2.08 \mathrm{~s}+0.36)
$$

The step response of the system is shown in figure (1): 


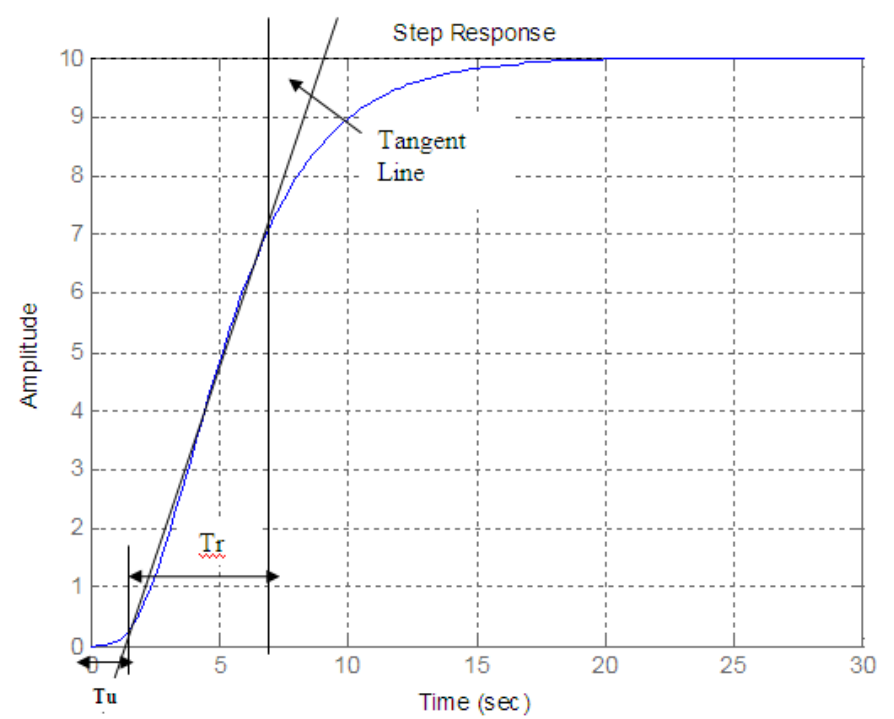

Figure (1): High altitude pitch S shape step response before PID controller

The closed loop Transfer function with unity feedback before PID controller is:

3.6

$\mathrm{TF}=$

$S^{\wedge} 4+3.36 s^{\wedge} 3+4.08 s^{\wedge} 2+2.08 s+3.96$

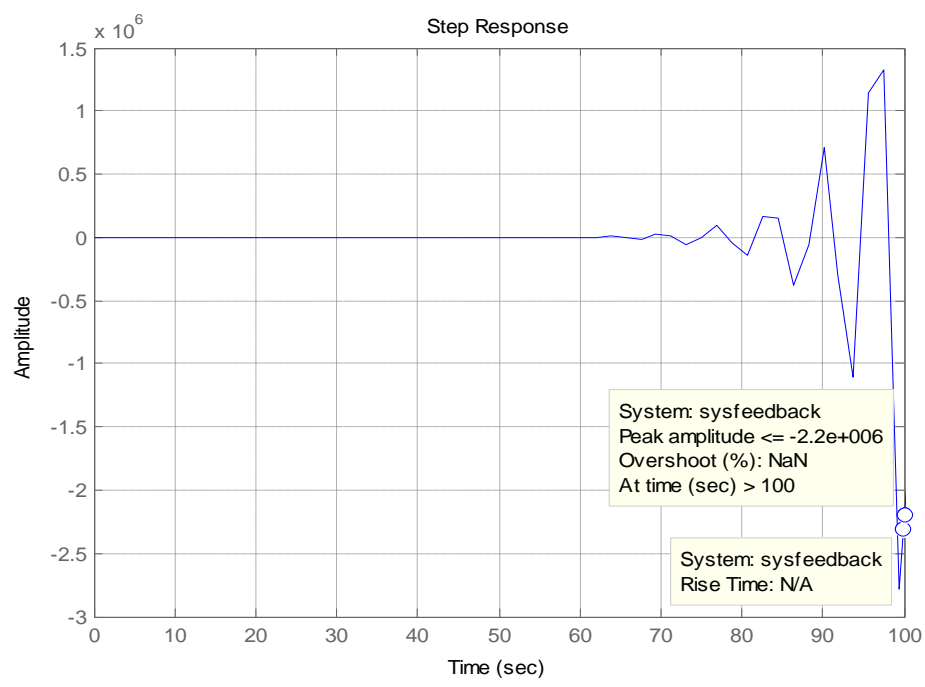

Figure (2): Closed loop step response before PID controller

As shown in figure (2) it is clear that the system before applying any controller is absolutely unstable, because of that response we must enter the PID controller to the pitch TF system.

We will implement the PID controller(C(s)) in series to the aircraft pitch system $(\mathrm{Gp}(\mathrm{s}))$ with the unity feedback architecture to achieve the desired system behavior [2].

Before applying Ziegler Nicholas method to get the values of the PID parameters (kp, ki and kd) first it is assumed that values are equal to unity for simplicity. Then the TF of the PID is:

$C(s)=\frac{s^{2}+s+1}{s}$

The system TF and closed loop Step response after a unity PID controller was injected with unity feedback will be: 


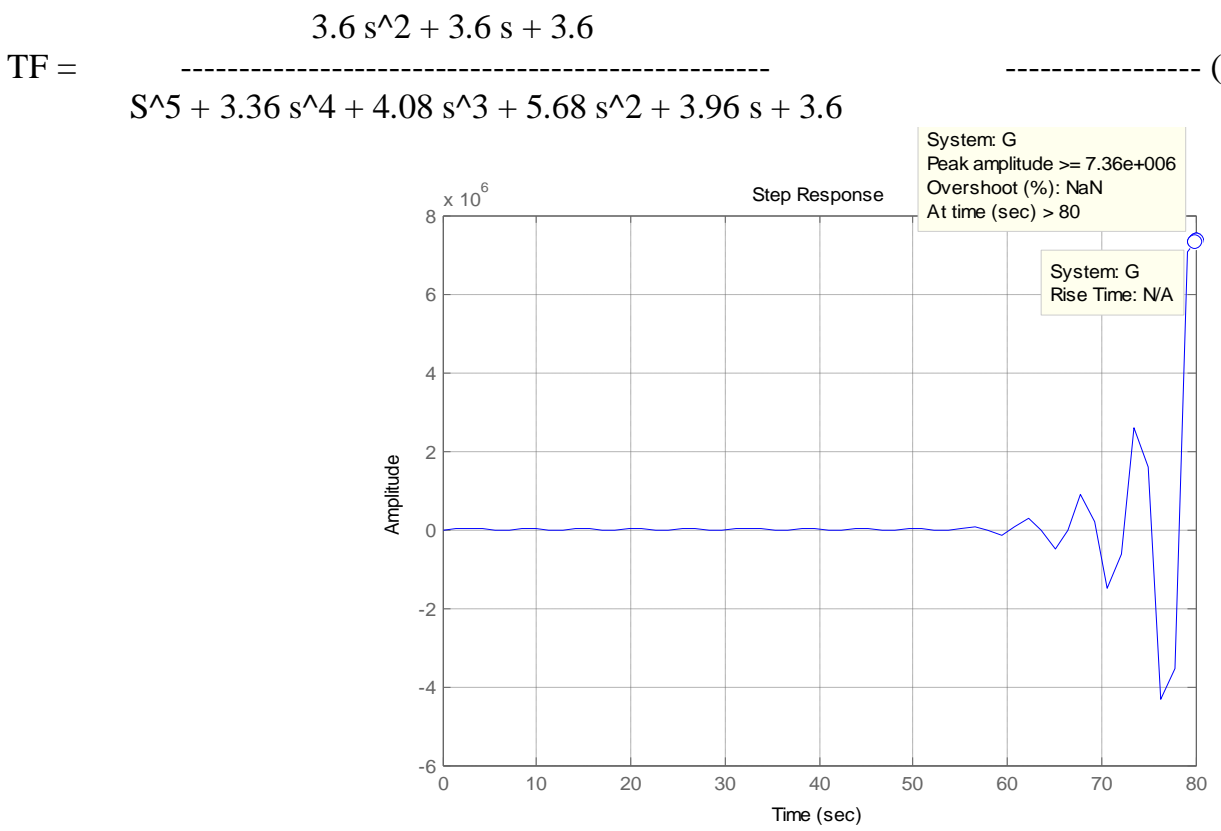

Figure (3): Pitch system after unity PID controller is inserted

\section{Methodology}

From step response of figure (3) unity PID parameters are not a good choice to drive the aircraft pitch system to be stable. Ziegler Nicholas technique must be used to find optimal PID parameters.

In this paper will discusses the one of methods Ziegler Nicholas technique that stipulating a unit-step response curve of the system must look like S-shaped, as shown in fig (1) the high altitude pitch step response before PID controller is look like S- shape .

To apply Zeigler tuning method will first drawing a tangent line at the inflection point of the S-shaped curve, and then determining the intersections of the tangent line with the time axis and line $\mathrm{c}(\mathrm{t})=\mathrm{K}$, as shown in Figure (1).

As known, the transfer function for a PID controller is the following [3]:

$C(S)=K_{P}+\frac{K_{I}}{S}+K_{d} S=\frac{K_{d} S^{2}+K_{p} S+K_{i}}{S}$

When using Kc, Ti and Td the PID controller transfer function will be:

$$
G_{\mathrm{C}}(s)=K_{\mathrm{C}}\left(1+\frac{1}{T_{\mathrm{I}}}+T_{\mathrm{D}} s\right)
$$
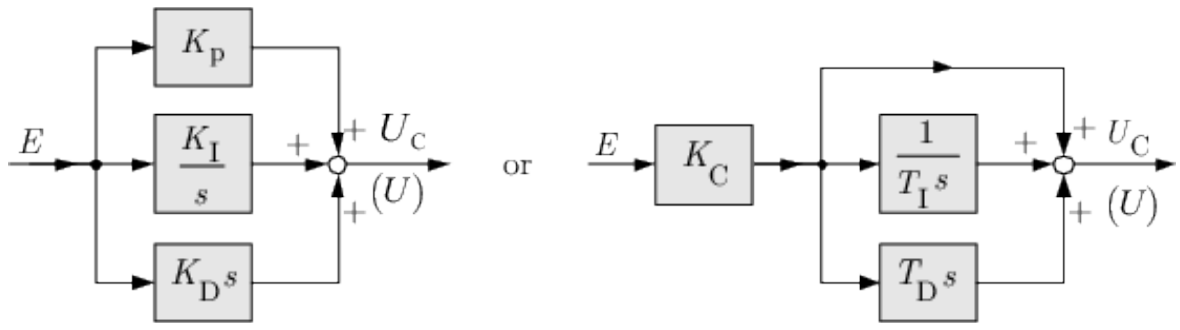

Figure (4): block diagram of the PID controller [3] 
$K_{\mathrm{C}}=K_{\mathrm{P}}$

$T_{\mathrm{I}}=\frac{K_{\mathrm{p}}}{K_{\mathrm{I}}}$

$T_{\mathrm{D}}=\frac{K_{\mathrm{D}}}{K_{\mathrm{p}}}$

Table (1): tuning parameters for Ziegler Nicholas method [4]

\begin{tabular}{|l|c|l|l|}
\hline & $\mathrm{K}_{\mathrm{C}}$ & \multicolumn{1}{|c|}{$\mathrm{T}_{\mathrm{I}}$} & \multicolumn{1}{c|}{$\mathrm{T}_{\mathrm{D}}$} \\
\hline $\mathrm{P}$ & $\frac{1}{\mathrm{Kp}} \frac{\mathrm{T}_{\mathrm{r}}}{\mathrm{T}_{\mathrm{u}}}$ & - & - \\
\hline PI & $\frac{0.9}{\mathrm{Kp}} \frac{\mathrm{T}_{\mathrm{r}}}{\mathrm{T}}$ & $3.33 \mathrm{~T}_{\mathrm{u}}$ & - \\
\hline PID & $\frac{1.2}{\mathrm{Kp}} \frac{\mathrm{T}_{\mathrm{u}}}{\mathrm{T}}$ & $2 \mathrm{~T}_{\mathrm{u}}$ & $0.5 \mathrm{~T}_{\mathrm{u}}$ \\
\hline
\end{tabular}

From figure (1):

$\operatorname{Tr}=$ rise time $\operatorname{Tr}=7.7$ and $\mathrm{Tu}$ is delay time $\mathrm{Tu}=1.5$

The PID case:

$\mathrm{Kc}=(1.2 / 10) *(7.7 / 1.5)=0.616$

$\mathrm{T}_{\mathrm{I}}=2 \mathrm{Tu}=3$

$\mathrm{T}_{\mathrm{D}}=0.5 \mathrm{Tu}=0.75$

Then the PID controller is:

$$
\begin{aligned}
& G_{\mathrm{C}}(s)=K_{\mathrm{C}}\left(1+\frac{1}{T_{\mathrm{I}} s}+T_{\mathrm{D}} s\right) \\
& =0.616[1+(1 / 3 \mathrm{~s})+0.75 \mathrm{~s}]=0.616+0.616 / 3 \mathrm{~s}+0.462 \mathrm{~s} \\
& \mathrm{Gc}(\mathrm{s})=\quad 0.616 \mathrm{~s}+0.205+0.462 \mathrm{~s}^{\wedge} 2 \\
& -\mathrm{S}
\end{aligned}
$$

When connected the PID controller with the pitch plant, the step response and the final transfer function will be:

$\mathrm{TF}=$

$$
1.663 \mathrm{~s}^{\wedge} 2+2.218 \mathrm{~s}+0.738
$$

$\mathrm{S}^{\wedge} 5+3.36 \mathrm{~s}^{\wedge} 4+4.08 \mathrm{~s}^{\wedge} 3+3.743 \mathrm{~s}^{\wedge} 2+2.578 \mathrm{~s}+0.738$

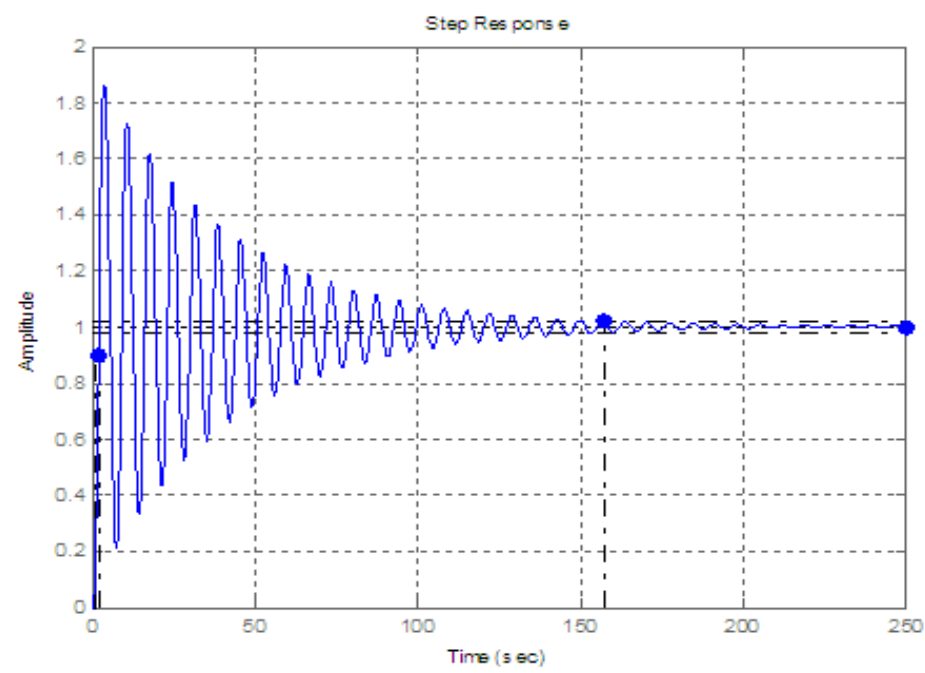

Fig (5): Step response of the system after PID tuning With Ziegler Nicholas method 
From figure (5) Since Kp and KI increase the overshoot, the half or less may be taken so take $\mathrm{Kp}=0.3$ and $\mathrm{KI}=0.1$, and the PID transfer function will be:

$\mathrm{Gc}(\mathrm{s})=\frac{0.46 \mathrm{~s}^{\wedge} 2+0.3 \mathrm{~s}+0.1}{---------}$

And the final TF and step response of the all system well be: $1.663 \mathrm{~s}^{\wedge} 2+1.08 \mathrm{~s}+0.36$

$\mathrm{TF}=$ $\mathrm{S}^{\wedge} 5+3.36 \mathrm{~s}^{\wedge} 4+4.08 \mathrm{~s}^{\wedge} 3+3.743 \mathrm{~s}^{\wedge} 2+1.44 \mathrm{~s}+0.36$

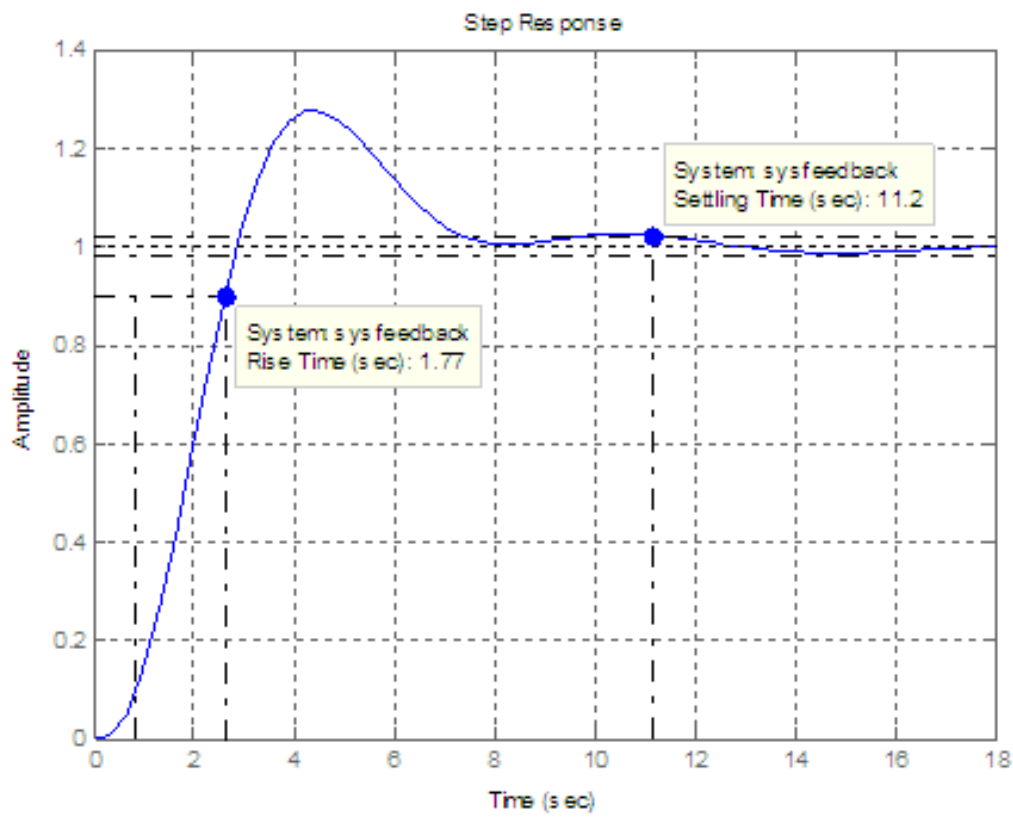

Figure(7):step response for the tuned system

With $\operatorname{Tr}=1.77$ and $\mathrm{Ts}=11.2$

\section{Results}

The fourth order spacecraft system is usually connected in a closed loop system. Its time response is an important issue for control system designers.

The response of the plant without a controller has an unstable performance as shown in figure (2). This requires an insertion of a controller to improve its response characteristics. When the PID controller was used with unity parameters the response was still unstable. This means that the PID parameters should be chosen perfectly to obtain the desired response. Ziegler Nicholas was used to determine the proper parameters namely $\mathrm{Kp}=0.3$ and $\mathrm{KI}=0.12$ and $\mathrm{Kd}=0.462$.

These values when used in the PID controller the performance and the time response of the system were acceptable. The time response due to the step input is shown in figure (7).

\section{Conclusion}

The spacecraft pitch system was discussed in many previous papers and a PID controller for this system was also discussed many times in many papers, but improving the controller by Ziegler-Nichols method is rare. This paper implemented the Ziegler Nicholas tuning method to the spacecraft pitch controller system to improve its performance. The results obtained have shown that the parameters chosen by Ziegler Nicholas may not be the optimal as this method depends on the graphical values measured from the s-shape of the step response. A bit change was added to these parameters so as to have a better performance. 


\section{References}

[1]. http://facultad.bayamon.inter.edu/arincon/pitch\%20control\%20system\%20for\%20high-altitude\%20aircraft.pdf.

[2]. Katsuhiko Ogata, "Modern Control Engineering", Prentice-Hall, Inc., 1997 pp 60-63

[3]. F Haugen - 2010, "The Good Gain method for PI (D) controller tuning" Available at: http://techteach.no/publications/articles/good_gain_method/go

[4]. Empirical tuning methods, http://www.atp.ruhr-uni-bochum.de/rt1/syscontrol/node64.html, accessed on 15 Sep 2014.

[5]. Hugh Jack, "Dynamic System Modelling and Control ", Copyright 1993-2003 Hugh Jack, pp 54-55.

[6]. Richad C Dorf and Robert H. Bishop, Modern Control Systems, Pearson Education Inc, 2008.

[7]. P.N Paraskevopouls, Modern Control Engineering, Marcel Dekker Inc, 2002. 